\title{
Estimation of Radon Concentration in Soil Samples from Cameron Highlands, Malaysia
}

\author{
Murtadha Shakir. Aswood", *, Mohamad Sahimi. Jaafar², Najeba Salih ${ }^{3}$ \\ ${ }^{1}$ Department of Physics, College of Education, University of Al-Qadisiyah, Al-Qadisiya, Iraq \\ ${ }^{2}$ School of Physics, Universiti Sains Malaysia, Penang, Malaysia \\ ${ }^{3}$ Department of Physics, College of Science, Faculty of Science and Health, Koya University, Koya, Iraq \\ Email address: \\ murtadhababylon@gmail.com (M. S. Aswood) \\ ${ }^{*}$ Corresponding author
}

\section{To cite this article:}

Murtadha Shakir. Aswood, Mohamad Sahimi. Jaafar, Najeba Salih. Estimation of Radon Concentration in Soil Samples from Cameron Highlands, Malaysia. International Journal of Science, Technology and Society. Vol. 5, No. 1, 2017, pp. 9-12.

doi: $10.11648 /$ j.jists.20170501.12

Received: March 24,2017; Accepted: March 29, 2017; Published: April 15, 2017

\begin{abstract}
Concentrations of radon have been estimated in agricultural soil in Cameron Highlands in Pahang, Malaysia. CR39 plastic track detectors are used to measure concentration of radon rate in the soil samples. Results reveal that the mean radon concentrations in agricultural soil collected from Cameron Highlands are 198.44 $\pm 59.44 \mathrm{~Bq} \mathrm{~m}^{-3}$. These concentrations are below than the action levels of $200-600 \mathrm{~Bq} \mathrm{~m}^{-3}$ as recommended by ICRP. According to the results, the areas of study are safe and do not pose health risks to the population in those areas, and thus the soil can be used for construction materials.
\end{abstract}

Keywords: CR-39, Radon, Cameron Highlands

\section{Introduction}

Radon measurements are crucial in monitoring human health and safety. Exposure to radon and its daughters contributes to more than $50 \%$ of the total radiation dose received from natural sources by human beings (UNSCEAR, $2000) .{ }^{222} \mathrm{Rn}$ is produced by the alpha decay of ${ }^{226} \mathrm{Ra}$. It comes from the natural decay of uranium that is found in nearly all types of soil although the concentrations vary widely (NCRP, 1984). It typically moves up from the ground to the air. Radon decays with a half-life of 3.8 days which produces short daughters namely, ${ }^{218} \mathrm{Po},{ }^{214} \mathrm{~Pb},{ }^{214} \mathrm{Bi}$ and ${ }^{214} \mathrm{Po}$. Some atoms leave the soil and enter the surrounding air or water. As a result, radon is available indoor and outdoor. Emission of alpha particles takes place within the lungs as they inhale radon progenies. The most important and dominant contributors to the inhalation dose are the decay products of radon. Radon and its decay products in the air form the main natural sources of irradiation in human. Radon concentrations are higher indoors, but there is a substantial concentration outdoors as well. Besides affecting the public, it is responsible for many cancer deaths among uranium miners
[UNSCEAR, 2000, Adams, 1991]. In this concern, studies on soil have been carried out in different parts of the world, and much data is available in the literature (Rafique et al., 2011; Saad et al., 2013; Al-Nafiey et al., 2014). The Kinta district has many tin mining sites and is expected to have high background radiation from minerals, such as monazite and zircon. Granite bodies form the Main Range on the east and the Kledang Range on the west of the Kinta District. Higher radiation levels are associated with igneous rocks such as granite. The main objective of this study is to assess the levels of radon in the soil samples collected from Cameron Highlands region of Pahang, as well as the results are compared with the allowable levels worldwide.

\section{Materials and Methods}

Study area

Cameron Highlands, which is a district in the state of Pahang, has a total area of 71,218 ha. Cameron Highlands is located between Kelantan and part of Kinta District (Perak) and is situated in a part of the northwestern tip in Pahang as showed in Figure 1. Furthermore, Cameron Highlands is a popular tourist 
and recreational area in addition to its being a key agricultural area for vegetables, flowers, and tea (Aswood et al., 2013).

\section{MAJOR AREAS OF AGRICULTURAL ACTIVITIES IN CAMERON HIGHLANDS}

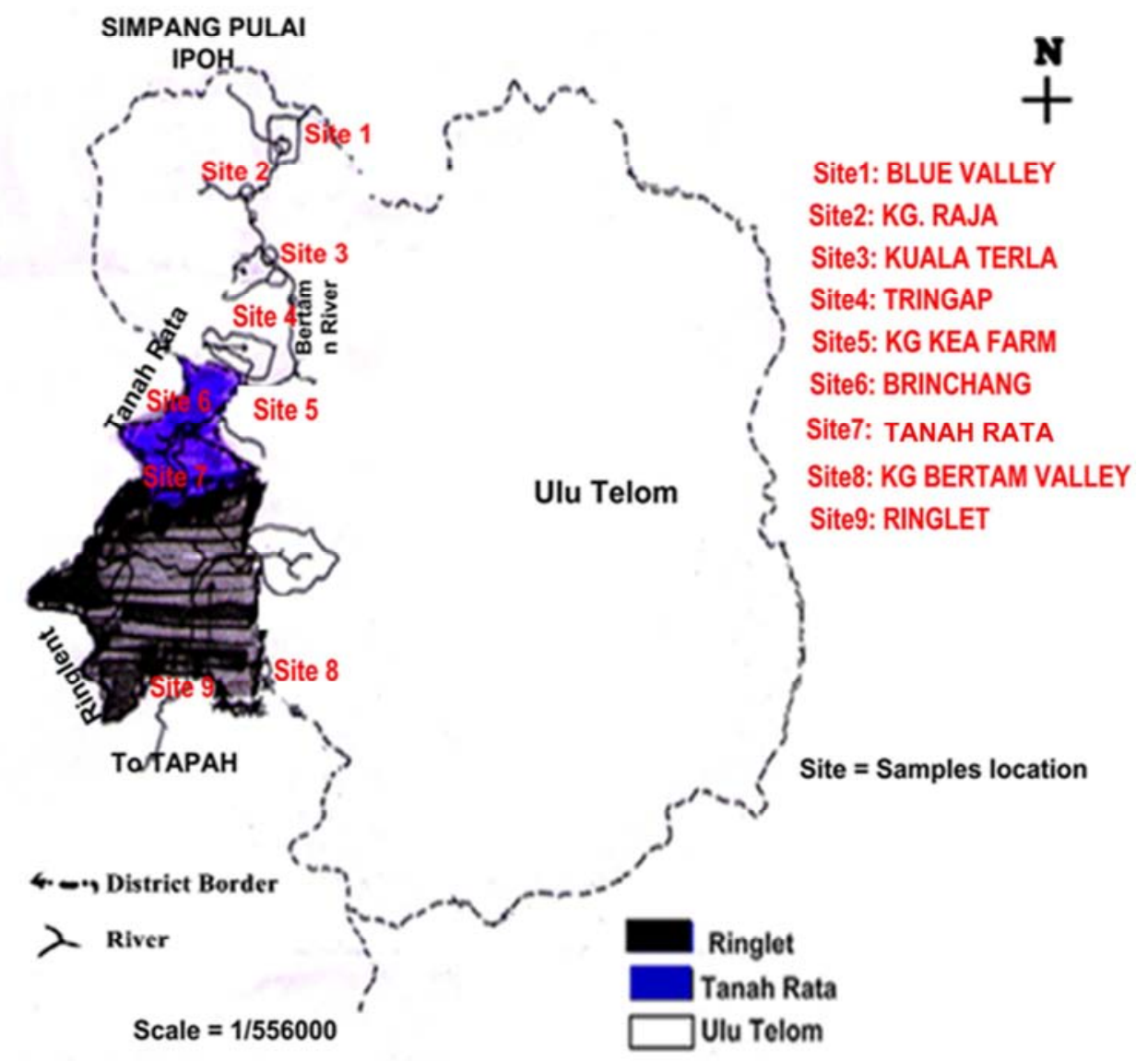

Figure 1. Map of Cameron highlands, Malaysia with sampling sites.

Collection and preparation of samples

Soil samples were collected from different parts of agricultural and non-agricultural areas in the Cameron Highlands. Samples were collected from the surface soil to a depth of $15 \mathrm{~cm}$ as showed in Figure 2. One $\mathrm{kg}$ of soil sample was cleaned, and stones, pebbles, and root parts were removed. Soil samples were oven-dried at $110^{\circ} \mathrm{C}$ for $24 \mathrm{~h}$ to remove moisture. Then, the soil samples were grinded and sieved through a $2 \mathrm{~mm}$ nylon mesh to remove large debris, stones, and pebbles.

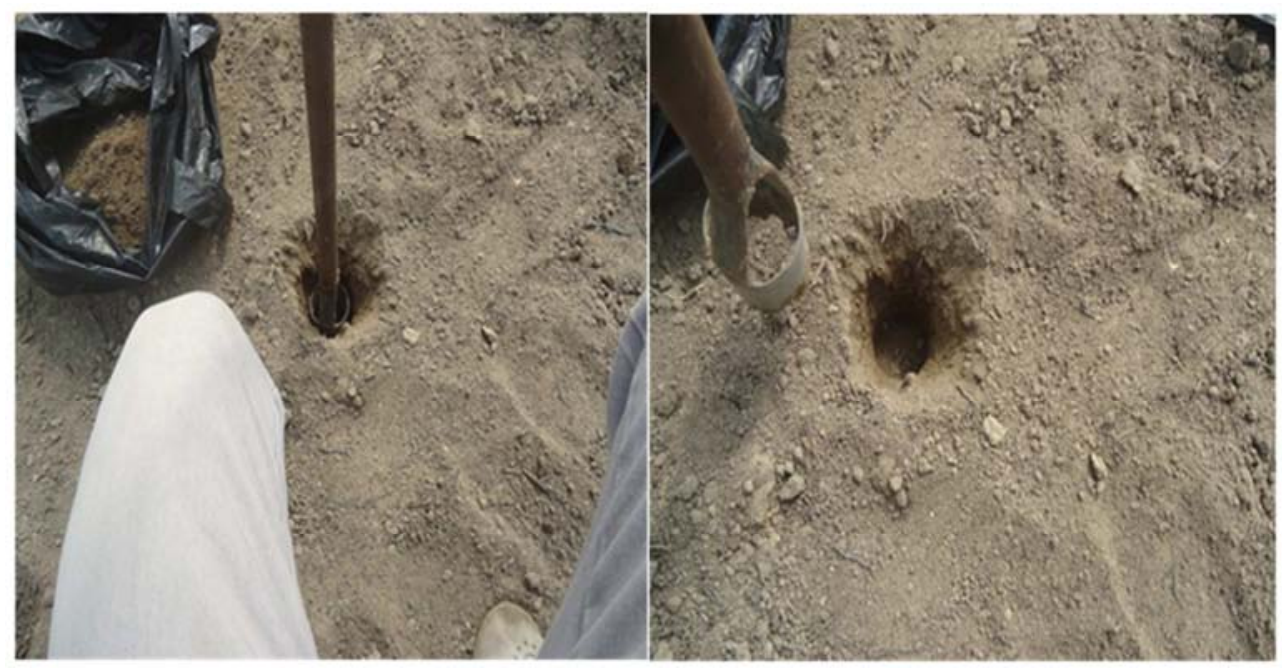

Figure 2. Illustration of use of hand corer for soil sampling. 


\section{CR-39 Detector}

The present research used the standard grade CR-39 solid state track detectors (SSTD) having thickness of $500 \mu \mathrm{m}$ produced by the Track Analysis Systems Ltd., Napier House, Meadow Grove, Bristol, UK. Large sheets of CR-39 were cut into small pieces, with each size of $1.5 \mathrm{~cm} \times 1.5 \mathrm{~cm}$. For measuring the radon concentration, the CR-39 detector was fixed inside the cans lid before closed the cans. The size of the cans used was $10 \mathrm{~cm}$ in height and a $5.5 \mathrm{~cm}$ inner diameter as shown in Figure 3. The CR-39s were stored in the cans for three months with the samples. After 90 days of exposure, the detectors from all the cans were retrieved. The CR-39 detectors were etched at several conditions. The optimum condition for the etching of the CR-39 detectors was $6.25 \% \mathrm{~N}-\mathrm{NaOH}$ at $70^{\circ} \mathrm{C}$ with accuracy of $\pm 0.1^{\circ} \mathrm{C}$ and an etching time of $6 \mathrm{~h}$. After etching, the detectors were washed in distilled water and were then dipped for a few seconds in 3\% acetic acid solution. After that, the detectors were washed again and allowed to dry in air. The numbers of track in 40 fields were scanned for each detector using an optical microscope (400X objective lens) which was used to determine the track density per $\mathrm{cm}^{2}$ (Aswood et al., 2014). The CR-39 detector records the tracks of alpha particles emitted by radon gas. The track density $\rho$ (track $\mathrm{cm}^{-2}$ ) was determined from the formula below.

$$
\rho=\frac{A_{n}}{N_{v}}
$$

where $A_{n}$ is the average number of total tracks and $\boldsymbol{N}_{v}$ is the fields of view. The radon concentration $C_{R n}\left(\mathrm{~Bq} \mathrm{~m}^{-3}\right)$ was calculated using the formula given by (Ramu et al., 1988).

$$
C_{R n}=\frac{\rho}{K \times T}
$$

where $K$ is the calibration factor $\left(\operatorname{tr} . \mathrm{cm}^{-2}\right.$ per Bq. $\left.\mathrm{m}^{-3} . \mathrm{d}\right)$ and $T$ is the exposure time (d). In this formula, $K$ is the calibration factor of CR-39 and has a value of 0.024 (tr.cm ${ }^{-2}$ perBq. $\boldsymbol{m}^{-3} \cdot d$ ) (Al-Nafiey et al., 2012).

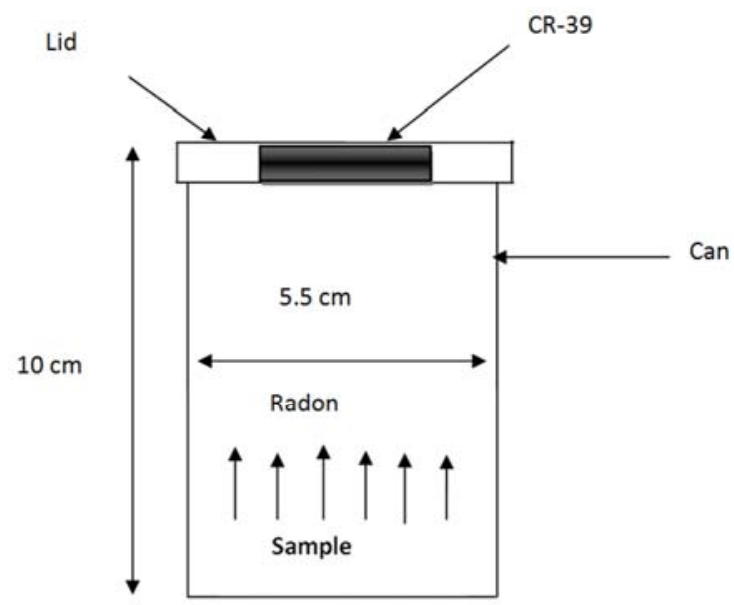

Figure 3. The experimental can for the measurement of radon.

\section{Results and Discussion}

Radon concentrations in agricultural soil samples collected from Cameron Highlands are presented in Table 1. The radon concentrations varied from 67.22 to $295.07 \mathrm{~Bq} \mathrm{~m}^{-3}$, with a mean and standard deviation of 198.44 $\pm 59.44 \mathrm{Bqm}^{-3}$. Based on the results, it can be seen that the radon concentration varies significantly among the samples of both regions. As previously mentioned, it is clearly expected that the radon concentration due to the uranium and radium concentrations are present in these samples. On the other hand, the concentration of radon in soil and air varies over time, and the variations are associated with the physical nature of the soil and the environment although it also depends on many other parameters such as changes in air pressure, temperature, wind and moisture. Other most important factors that control the emanation of radon in soil are the grain size and shape. The UNSCEAR (2000) found that the relation between the grain size and emanation of radon is inversely proportional to grain size. The results exhibited normal levels of radon concentration from agricultural soil.

Table 1. Concentrations of ${ }^{222} R n$ in agricultural soil samples collected from Cameron Highlands.

\begin{tabular}{ll}
\hline Location & Rn-222 $\left(\mathbf{B q ~} \mathbf{~ m}^{-3}\right)$ \\
\hline Ulu Telom & \\
Blue Valley & 278.58 \\
Kg. Raja & 126.67 \\
Kg. Kuala Terla & 149.47 \\
Kg. Tringkap & 245.54 \\
Kg. Kea Farm & 220.80 \\
Tanah Rata & \\
Brinchang & 210.86 \\
Tanah Rata & 202.61 \\
Ringlet & \\
Ringlet & 245.54 \\
Kg. Bertam Valley & 133.26 \\
Mean & 198.44 \\
Std. Dev & 59.44 \\
Std. Error & 12.13 \\
\hline
\end{tabular}

Table 2, shows the comparison between radon concentrations in the present study with those elsewhere. The concentrations of radon in this area of study are remarkably lower than those for Pakistan, India, Egypt and Libya; whereas the values of radon are higher than those reported for Brazil (Rafique et al., 2011, Binns et al., 1998, AbdElzaher, 2012, Mahur et al., 2013, Saad et al., 2013). Based on the comparison, it has been observed that there is also a variation in the values of radon levels among countries. This variation is due to the difference in the nature of the samples and the uranium content in the samples. However, these concentrations are found below than the action levels of 200 $600 \mathrm{~Bq} \mathrm{~m}^{-3}$ recommended by ICRP (1993). In general, the results are within the worldwide range values found in soil and are within the safety level. According to the results, the areas of study are safe and do not pose health risks to the population in those areas, and thus the soil can be used for construction materials. 
Table 2. A comparison between the radon concentrations in agricultural soil samples with the values reported for other countries.

\begin{tabular}{lllll}
\hline Country & ${ }^{222} \mathbf{R n}\left(\mathbf{B q ~}^{-3}\right)$ & & & References \\
\hline & Min & Max & Mean & \\
\hline Pakistan & - & - & 261.67 & Rafique et al., 2011 \\
Brazil & 4 & 404 & 69 & Binns et al., 1998 \\
Egypt & 3130 & 6970 & 5110 & Abd-Elzaher, 2012 \\
India & 177.5 & 583.4 & 330.5 & Mahur et al., 2013 \\
Libya (Benghazi) & 31.1 & 469 & 220.3 & \\
Libya (Al-Marj) & 59.3 & 515.8 & 325.5 & Saad et al., 2013 \\
Malaysia (Cameron Highlands ) & 67.219 & 295.068 & 198.442 & Present Study \\
\hline
\end{tabular}

\section{Conclusion}

The mean radon concentrations in agricultural soil collected from Cameron Highlands are 198.44 $\pm 59.44 \mathrm{~Bq} \mathrm{~m}^{-}$

${ }^{3}$. These concentrations are below than the action levels of $200-600 \mathrm{~Bq} \mathrm{~m} \mathrm{~m}^{-3}$ as recommended by ICRP (1993). In general, the results are within the worldwide average values found in soil; these results are within the safe limit.

\section{Acknowledgements}

This study was supported by the School of Physics and School of Chemical Sciences, Universiti Sains Malaysia. Financial support was provided by the School of Physics, Universiti Sains Malaysia 1001/PFIZIK 846086.

\section{References}

[1] Adams, V. D., 1991. Water and Wastewater examination manual, Lewis Publishers Inc, USA.

[2] Al-Nafiey, M. S. and Bauk, S. B., 2012. Design and Fabrication of New Radon Chamber for Radon Calibration Factor of Measurement. International Journal of Scientific e Engineering Research, 3 (10).

[3] Al-Nafiey, M. S., Jaafar, M. S. and Bauk, S., 2014. Measuring radon concentration and toxic elements in the irrigation water of the agricultural areas in Cameron Highlands, Malaysia. Sains Malaysiana, 43 (2), pp. 227-231.

[4] Aswood, M. S., Jaafar, M. S. and Bauk, S., 2013. Assessment of radionuclide transfer from soil to vegetables in farms from Cameron Highlands and Penang,(Malaysia) using neutron activation analysis. Applied Physics Research, 5 (5), p.85.

[5] Aswood, M. S., Jaafar, M. S. and Bauk, S., 2014, June. Measuring Radon Concentration Levels in Fertilizers Using CR-39 Detector. In Advanced Materials Research (Vol. 925, pp. 610-613).

[6] Rafique, M., Rahman, S. U., Mahmood, T., Rahman, S. and Rehman, S. U., 2011. Radon exhalation rate from soil, sand, bricks, and sedimentary samples collected from Azad
Kashmir, Pakistan. Russian Geology and Geophysics, 52(4), pp. 450-457.

[7] Saad, A. F., Abdallah, R. M. and Hussein, N. A., 2013. Radon exhalation from Libyan soil samples measured with the SSNTD technique. Applied Radiation and Isotopes, 72, pp. 163-168.

[8] UNSCEAR, 2000. Report to the General Assembly with Scientific Annexes, United Nations. Annexure B. pp. 84-156.

[9] Mahur, A. K., Gupta, M., Varshney, R., Sonkawade, R. G., Verma, K. D., \& Prasad, R. (2013). Radon exhalation and gamma radioactivity levels in soil and radiation hazard assessment in the surrounding area of National Thermal Power Corporation, Dadri (UP), India. Radiation Measurements, 50, 130-135.

[10] Rafique, M., Rahman, S. U., Mahmood, T., Rahman, S., \& Rehman, S. U. (2011). Radon exhalation rate from soil, sand, bricks, and sedimentary samples collected from Azad Kashmir, Pakistan. Russian Geology and Geophysics, 52 (4), 450-457.

[11] Abd-Elzaher, M. (2012). An Overview on studying ${ }^{222} \mathrm{Rn}$ Exhalation Rates using Passive Technique Solid-State Nuclear Track Detectors. American Journal of Applied Sciences, 9 (10). 1653-1659.

[12] Binns, D. A. C., Figueiredo, N., Melo, V. P., \& Gouvea, V. A. (1998). Radon-222 measurements in a uranium-prospecting area in Brazil. Journal of Environmental Radioactivity, 38 (2), 249-254.

[13] ICRP, International Commission on Radiological Protection, (1993). International Commission on Radiological Protection for Protection against Radon at home and at work. ICRP publication 65, Pergamon Press, oxford, UK.

[14] NCRP, National Council on Radiation Protection and Measurements, (1984). Exposures from the Uranium Series with Emphasis on Radon and Its Daughters, NCRP Report No. 77 Bethesda, Maryland.

[15] UNSCEAR, (2000). United Nations Scientific Committee on the Effect of Atomic Radiation Sources, Effects and Risks of Ionizing Radiation. Report to the General Assembly, with Scientific Annexes, United Nations, New York. 